\title{
Paper A New CPW-fed Patch Antenna for UWB Applications
}

\author{
Purnima Sharma ${ }^{1}$, Santosh Kumar Jha ${ }^{2}$, and Partha Pratim Bhattacharya ${ }^{1}$ \\ ${ }^{1}$ Department of ECE, CET, Mody University of Science and Technology, Lakshmangarh, Rajasthan, India \\ ${ }^{2}$ Department of ECE, Sphoorthy Engineering College, Telangana, Hyderabad, India
}

\begin{abstract}
In this paper, the design and analysis of a compact size coplanar waveguide (CPW)-fed antenna for ultrawideband (UWB) applications is presented. The antenna has a compact size of $20 \times 20 \times 1.5 \mathrm{~mm}$ and provides a good impedance matching over the entire bandwidth of 3.2-14.3 GHz. The characteristics parameters, i.e. return loss, VSWR and radiation pattern, are analyzed using HFSS 11.0 software.
\end{abstract}

Keywords-planar antenna, ultra wideband, wireless communication.

\section{Introduction}

Ultra-Wide Band (UWB) technology is best suitable candidate for future communication systems, i.e. vehicular radar system (20-29 GHz), due to its advantages like low power consumption, low cost for short range communication and highly secure communication [2]. UWB antennas have wide application in wireless communication, medical equipment, remote sensing, etc. A challenge while designing UWB antenna is to achieve compact size, good impedance over wide bandwidth and stable radiation pattern [2]. Multiband antenna is proposed for similar applications in [3].

\section{Related Work}

In literature a variety of UWB antennas have been reported, i.e. CPW-fed compact, which gives wide 2.6-13.04 GHz bandwidth [4]. In [5], an UWB antenna with slotted radiating patch has been demonstrated. In [6] an optimization algorithm based ultra wideband antenna is presented. A triangular shaped ground plane based antenna suitable for UWB communication has been reported in [7]. Si et al. have used circular disc and split ring resonator to design UWB aerial with $182 \%$ wider bandwidth [8]. The concept of coupling between rectangular slot and tuning stub has been utilized to achieve UWB performance in [9]. In [10], a radiating patch with arc-shaped ground plane has been demonstrated, which is suitable for ultra-wideband applications.

The hexagonal-shaped microstrip fractal antenna powered through CPW-fed structure for UWB applications has been reported in [11]. A rectangular-shaped compact CPW-fed antenna has been demonstrated which is suitable for UWB and WLAN applications [12]. Another slotted rectangular patch antenna for WLAN application is presented in [13]. This has a simple structure and bandwidth of $2.06 \mathrm{GHz}$. For portable mobile communication, a tapered patch and ground plane with slots is presented, which gives $164 \%$ wider bandwidth [14].

\section{Design of Proposed Antenna}

The proposed slotted CPW-fed patch made on a FR4 glassepoxy laminate is presented in Fig. 1.

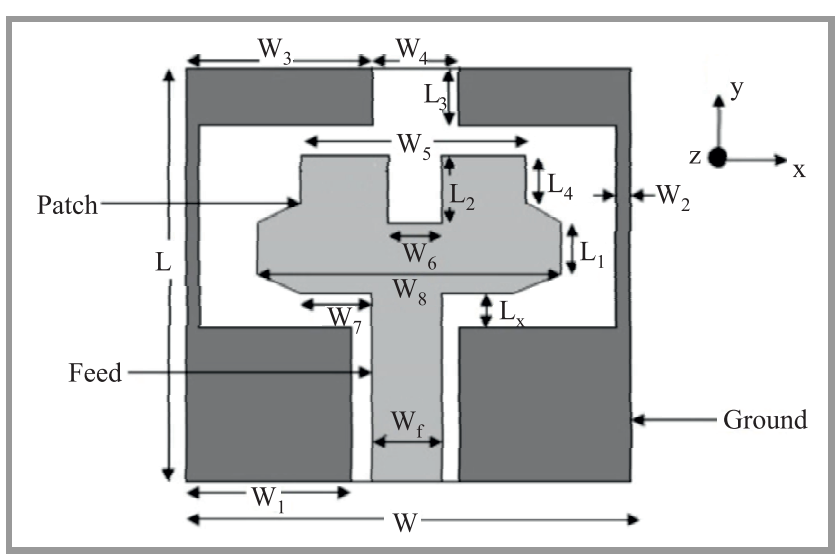

Fig. 1. Geometry of proposed CPW-fed patch antenna.

In design a $20 \times 20 \mathrm{~mm}$, substrate size was considered as requirement. The single side height is typical $1.5 \mathrm{~mm}$, with dielectric constant 4.4 and loss tangent 0.02. Slotted rectangular patch is chosen to achieve wide impedance bandwidth in planar antennas. The patch size is of $6 \times 15 \mathrm{~mm}$ wider. Two equal finite ground planes are placed on each side of the CPW-fed, extended upward to utilize the area (Fig. 1). The CPW-fed is used as it provides less radiation loss together with low dispersion and good impedance matching. The coplanar waveguide fed is in the $\mathrm{X}-\mathrm{z}$ plane. The width of the CPW-fed line is fixed at $3 \mathrm{~mm}$ to achieve $50 \Omega$ characteristic impedance. The feed line length is $9 \mathrm{~mm}$. The whole dimensions are listed in Table 1.

\section{Simulation and Results}

To evaluate antenna performance, a simulation study is carried out using finite element method based HFSS 11.0 software. The parameters like return loss, VSWR, current dis- 
Table 1

Antenna dimensions

\begin{tabular}{|l|c|c|c|c|c|c|c|c|c|c|}
\hline Parameter & $\mathrm{W}_{1}$ & $\mathrm{~W}_{2}$ & $\mathrm{~W}_{3}$ & $\mathrm{~W}_{4}$ & $\mathrm{~W}_{5}$ & $\mathrm{~L}_{1}$ & $\mathrm{~L}_{x}$ & $\mathrm{~W}_{7}$ & $\mathrm{~W}_{8}$ & $\mathrm{~L}_{4}$ \\
\hline \hline Value $[\mathrm{mm}]$ & 8.1 & 0.5 & 7 & 6 & 11 & 2 & 1 & 4 & 15 & 2 \\
\hline
\end{tabular}

tribution and radiation pattern are obtained. In order to improve the antenna performance, the parametric study is carried out. The parameters chosen for parametric study are slot width $\mathrm{W}_{6}$, slot length $\mathrm{L}_{2}$ and ground plane length $\mathrm{L}_{3}$. The other values have no significant contribution in the performance characteristics and are kept constant as indicated in Table 1. Figures 2-4 show the simulation results of return loss at different values.

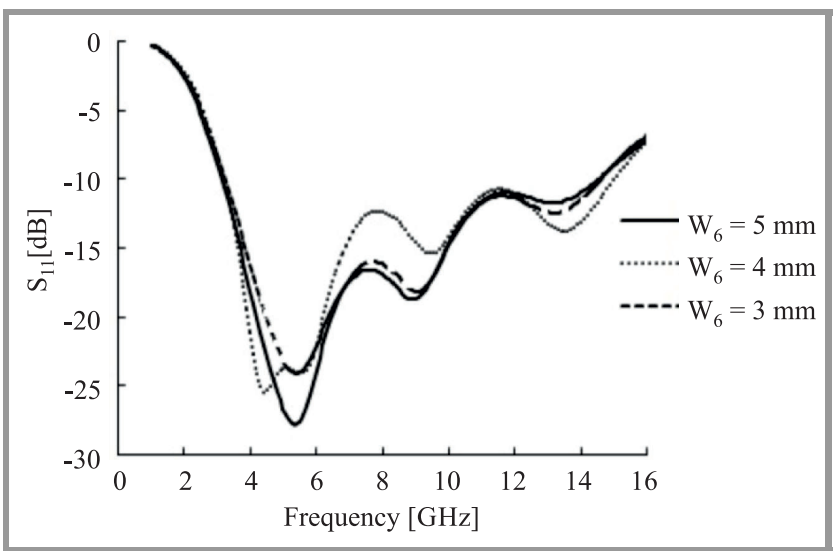

Fig. 2. Effect of slot width $\mathrm{W}_{6}$ on return loss for $\mathrm{L}_{2}=1.5 \mathrm{~mm}$ and $\mathrm{L}_{3}=0.5 \mathrm{~mm}$.

Figure 2 shows the effect of different slot width $\mathrm{W}_{6}$ on return loss. This parameter affects the return loss characteristics over the entire bandwidth. The minimum values of return loss was observed by keeping $\mathrm{W}_{6}=5 \mathrm{~mm}$. The return loss values are $-27.8,-18.2$ and $-12.5 \mathrm{~dB}$ at $5.3,9$, and $13.2 \mathrm{GHz}$, respectively.

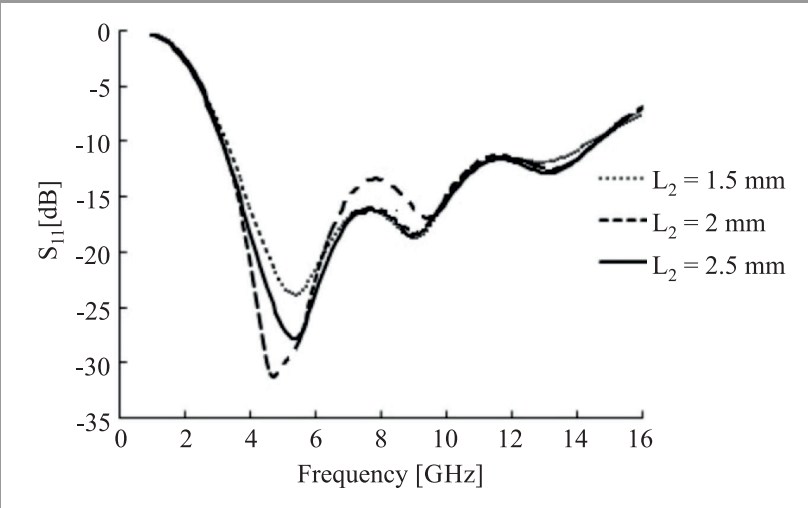

Fig. 3. Effect of slot length $\mathrm{L}_{2}$ on return loss $\mathrm{S}_{11}$ for $\mathrm{W}_{6}=5 \mathrm{~mm}$ and $\mathrm{L}_{3}=0.5 \mathrm{~mm}$.

The effect of varying slot length $L_{2}$ on return loss is shown in Fig. 3. This parameter affects the performance of antenna near lower operating frequency. A significant change in results can be observed with change in $\mathrm{L}_{2}$. The desired performance is found for $\mathrm{L}_{2}=2.5 \mathrm{~mm}$. The values of return losses are $-24,-18.7$ and $-12 \mathrm{~dB}$ at $5.4,9$, and $12.9 \mathrm{GHz}$, respectively.

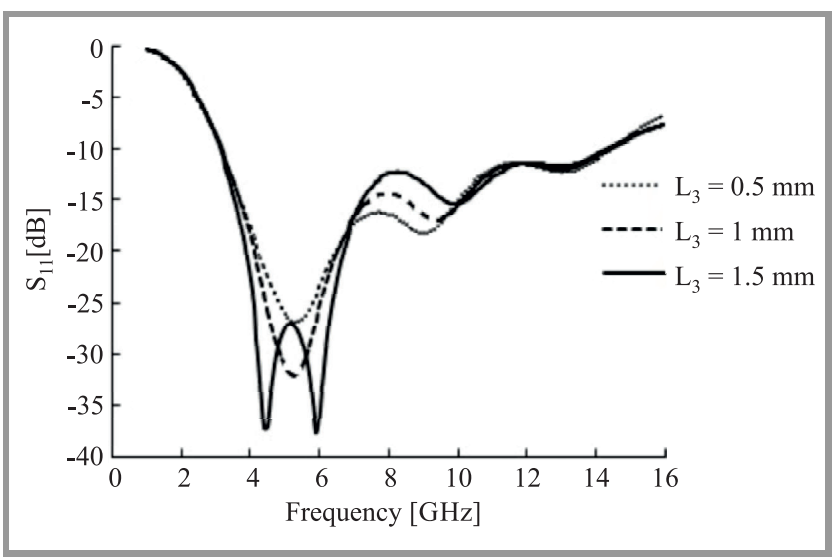

Fig. 4. Effect of ground plane length $\mathrm{L}_{3}$ on return loss for $\mathrm{W}_{6}=5 \mathrm{~mm}$ and $\mathrm{L}_{2}=2.5 \mathrm{~mm}$.

The ground plane length also has an impact on antenna performance as shown in Fig. 4. It can be seen that by keeping $\mathrm{L}_{3}=1.5 \mathrm{~mm}$ three significant bands are observed. The corresponding return loss values are $-37.1,-37.6$ and $-15.4 \mathrm{~dB}$ at $4.5,5.9$, and $10 \mathrm{GHz}$, respectively.

Figure 5 shows the antenna performance by keeping optimized parameter values as $\mathrm{L}_{2}=2.5, \mathrm{~L}_{3}=1.5$ and $W_{6}=$ $5 \mathrm{~mm}$. This antenna gives a wideband performance over an entire range of 3.2-14.3 GHz. Three significant bands are obtained at $4.5,5.9$ and $10 \mathrm{GHz}$. It has three dominant frequencies at $4.5,5.9$, and $10 \mathrm{GHz}$ and the overlapping of these make the suitable for UWB.

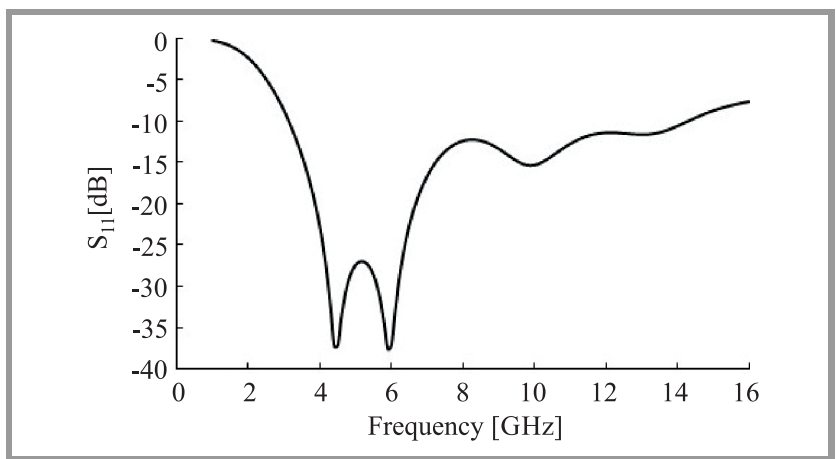

Fig. 5. Simulated return loss for optimized parameters.

While comparing the similar type of aerials existing in the literature, the proposed antenna shows an improvement of 6-27\% [4], [9] in bandwidth. 


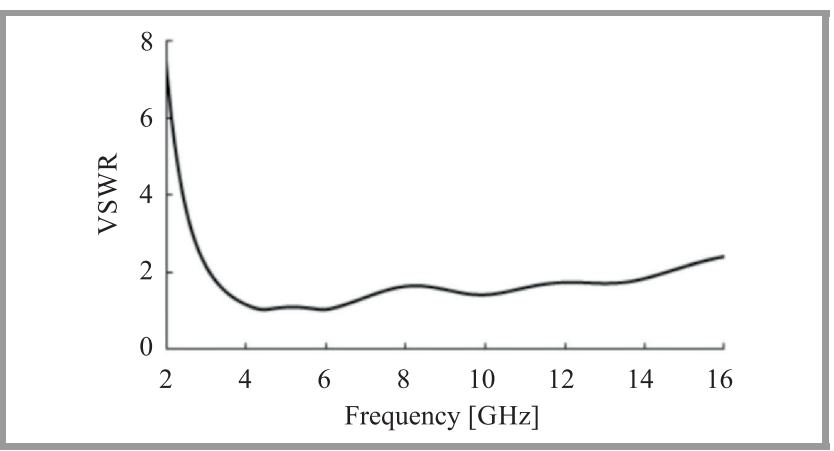

Fig. 6. VSWR versus frequency plot of proposed antenna.

In addition, the proposed antenna performance in terms of VSWR is shown in Fig. 6. The values of VSWR are 1.1, 1 and 1.41 at $4.5,5.9$, and $10 \mathrm{GHz}$, respectively. The 2:1 VSWR bandwidth is $11.1 \mathrm{GHz}$.

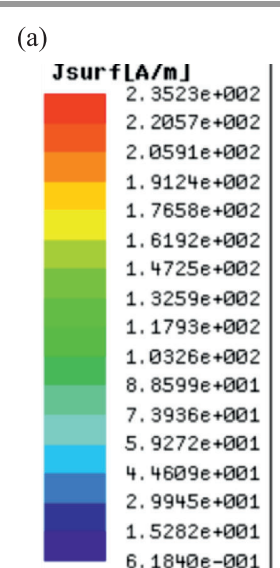

(b)

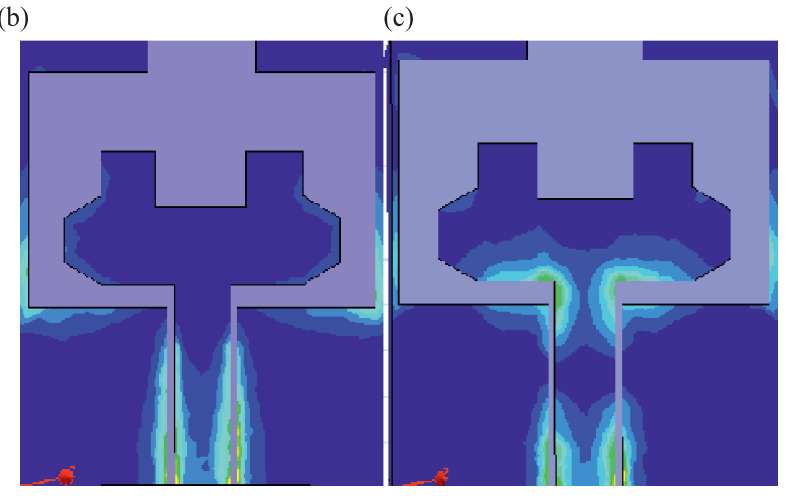

Fig. 7. Surface current flow on the antenna at: (a) 4.5, (b) 5.9, and (c) $10 \mathrm{GHz}$. (See color pictures online at www.nit.eu/ publications/journal-jtit)

Figure 7 presents the current distribution at different resonant frequencies: 4.5, 5.9, and $10 \mathrm{GHz}$. At $4.5 \mathrm{GHz}$, the electric current density is concentrated mainly on the side and upper edges of the ground plane, lower portion of patch and feed line. As shown in Fig. 7b, at 5.9 GHz current distribution is mainly concentrated on the side edges of patch, side vertical edges of ground plane and feed line. At $10 \mathrm{GHz}$ current density is mainly concentrated on the patch and feed line as shown in Fig. 7c. (a)
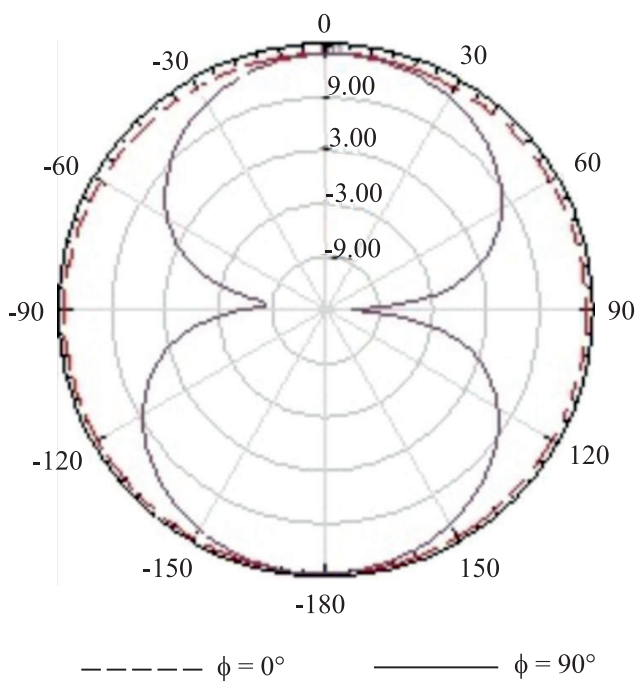

(b)

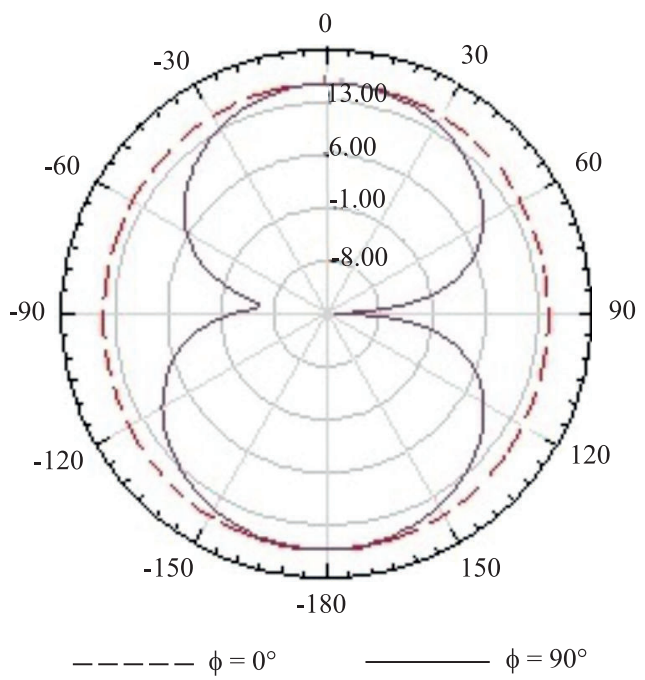

(c)

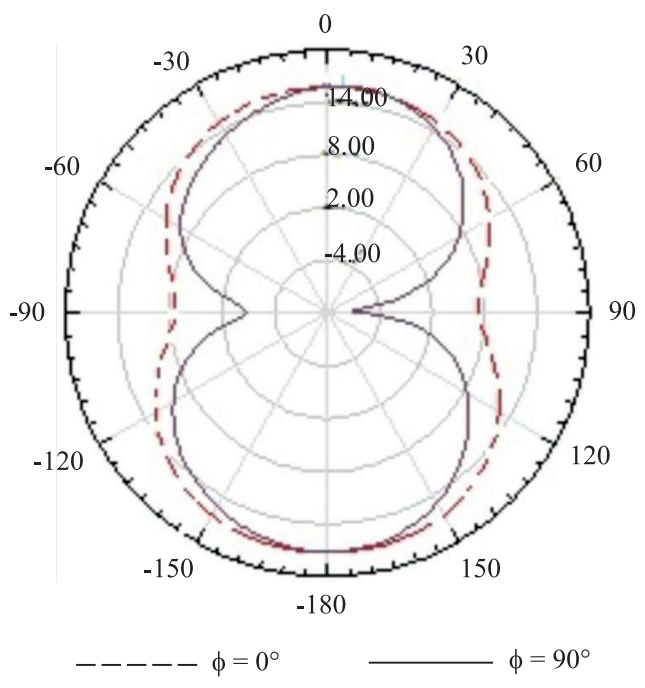

Fig. 8. Radiation pattern plots of designed antenna at: (a) 4.5, (b) 5.9 and (c) $10 \mathrm{GHz}$. 
Radiation pattern plots for designed antenna at 4.5, 5.9 and $10 \mathrm{GHz}$ are presented in Fig. 8. The simulated peak gains are $13.9,15.4$ and $15.7 \mathrm{dBi}$ respectively at 4.5, 5.9 and $10 \mathrm{GHz}$. One can found that the antenna has nearly good omnidirectional radiation pattern at 4.5 and $5.9 \mathrm{GHz}$ frequencies. At $10 \mathrm{GHz}$ the radiation pattern is deviated from that of omnidirectional.

\section{Conclusion}

In this paper, a new small size UWB antenna is proposed and analyzed. The antenna shows a good impedance bandwidth over the entire operating band of 3.2-14.3 GHz. Due to the compact size, wide impedance bandwidth, and nearly omnidirectional radiation properties, it is a good candidate for the applications in wireless communication.

\section{References}

[1] Federal Communications Commission Rules, Subpart F UltraWideband Operation, CFR47, Chapter I, Part 15, 2010.

[2] N. A. Touhami et al., "A compact CPW-fed planar pentagon antenna for UWB applications", Progress in Electromag. Res. C, vol. 46, pp. 153-161, 2014.

[3] P. Sharma, S. K. Jha, and P. P. Bhattacharya, "Design of a slotted triple band triangular patch antenna for 3G and WLAN applications", Microwave Rev., vol. 22, no. 1, pp. 23-26, 2016.

[4] A. K. Gautam, S. Yadav, and B. K. Kanaujia, "A CPW-fed compact UWB microstrip antenna", IEEE Antenn. and Wirel. Propag. Lett., vol. 12, pp. 151-154, 2013 (doi: 10.1109/LAWP.2013.224455).

[5] X. He, D. Shen, Q. Zhou, X. Zhang, J. Zeng, and Y. Lv, "A novel CPW-fed compact UWB microstrip antenna", in Proc. IEEE Int. Symp. on Antenn. and Propag. \& USNC/URSI Nat. Radio Science Meet., Vancouver, BC, Canada, 2015, pp. 1972-1973 (doi: 10.1109/APS.2015.7305375).

[6] J. Kim, T. Yoon, J. Kim, and J. Choi, "Design of an ultra wideband printed monopole antenna using FDTD and genetic algorithm", IEEE Microw. and Wirel. Compon. Lett., vol. 15, no. 6, pp. 395-397, 2005 .

[7] V. A. Shameenab et al., "A compact CPW fed slot antenna for ultra wide band applications", AEU - Int. J. of Electron. and Commun., vol. 66, no. 3, pp. 189-194, 2012.

[8] L. M. Si, H. J. Sun, Y. Yuan, and X. Lv, "CPW-fed compact planar UWB antenna with circular disc and spiral split ring resonators", in Proc. of Progress in Electromag. Res. Symp. PIERS 2009, Beijing, China, March 2009, pp. 502-505.

[9] J. William and R. Nakkeeran, "A compact CPW-fed UWB slot antenna with cross tuning stub", Progr. in Electromag. Res. C, vol. 13, pp. 159-170, 2010.

[10] F. Yu and C. Wang, "A CPW-fed novel planar ultra-wideband antenna with a band-notch characteristic", Radio Engin., vol. 18, no. 4, pp. 551-555, 2009

[11] K. K. Sawant and C. S. Kumar, "CPW fed hexagonal micro strip fractal antenna for UWB wireless communications", AEU - Int. J. of Electron. and Commun., vol. 69, no. 1, pp. 31-38, 2015 (doi: 10.1016/j.ane.2014.07.022).

[12] A. Subbarao and S. Raghavan, "Compact coplanar waveguidefed planar antenna for ultra-wideband and WLAN applications", Wirel. Pers. Commun., vol. 71, no. 4, pp. 2849-2862, 2013 (doi: 10.1007/s11277-012-0974-y)
[13] S. Sinha, B. Rana, C. Kumar Ghosh, and S. K. Parui, "A CPWfed microstrip antenna for WLAN application", Procedia Technol., vol. 4, pp. 417-420, 2012 (doi: 10.1016/j.protcy.2012.05.065).

[14] C. Deng, Y. J. Xie, and P. Li, "CPW-fed planar printed monopole antenna with impedance bandwidth enhanced", IEEE Antenn. and Wirel. Propag. Lett., vol. 8, pp. 1394-1397, 2009.

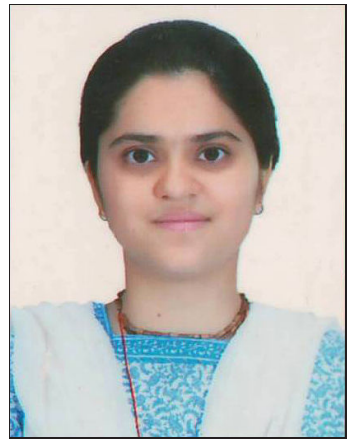

Purnima Sharma is currently working as Assistant Professor in Department of Electronics and Communication Engineering at Mody University of Science and Technology, Lakshmangarh, Rajasthan, India. She has received her B.Tech. degree in Electronics and Communication Engineering from MITS, Lakshmangarh, in 2009. She completed her M.Tech. in VLSI Design from NIT Hamirpur (H.P.), India, in 2011. She is pursuing Ph.D. from Mody University of Science and Technology, Lakshmangarh. Her research interests include antennas design for wireless applications. She has published many papers in refereed journals and conferences.

E-mail: purnimasharma.1487@gmail.com

Department of ECE, CET

Mody University of Science and Technology

Lakshmangarh, Rajasthan, India

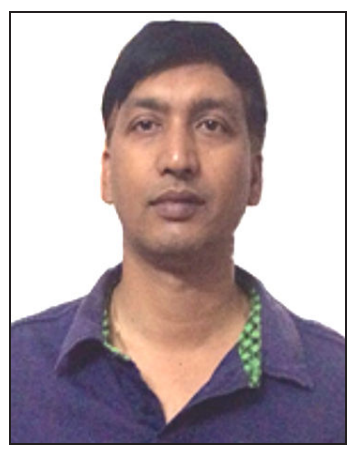

Santosh Kumar Jha is currently working as Professor in Sphoorthy Engineering College, Telangana, Hyderabad. He has 15 years of teaching experience. $\mathrm{He}$ did B.E. from SRTMU, Nanded with distinction. He has completed M.Tech. from UPTU Luchnow. He received Ph.D. from Babasaheb Bhimrao Ambedkar Bihar University, Muzaffarpur. He has published 24 papers in reputed journals. His research work includes design and analysis of microstrip antenna.

E-mail: ersantoshjha@yahoo.co.in

Department of ECE

Sphoorthy Engineering College

Telangana, Hyderabad, India

Partha Pratim Bhattacharya - for biography, see this issue, p. 37. 